\title{
A New Water Skink of the Genus Tropidophorus (Lacertilia: Scincidae) from Sulawesi, Indonesia
}

\author{
TSUTOMU HIKIDA ${ }^{1 *}$, AwAL RIYANTO ${ }^{2}$, AND HIDETOSHI OTA ${ }^{3}$ \\ ${ }^{1}$ Department of Zoology, Graduate School of Science, Kyoto University, Kitashirakawa- \\ Oiwakecho, Sakyo, Kyoto 606-8502, JAPAN \\ ${ }^{2}$ Research Centre for Biology, Museum Zoologicum Bogoriense, The Indonesian Institute \\ of Sciences, Widayasatwaloka Building, Jl. Raya Jakarta Bogor Km. 46, Cibinong 16911, \\ INDONESIA \\ ${ }^{3}$ Tropical Biosphere Research Center, University of the Ryukyus, Nishihara, Okinawa \\ 903-0213, JAPAN
}

\begin{abstract}
The population of the lygosomine genus Tropidophorus on Sulawesi, Indonesia, is usually referred to as $T$. grayi Günther, 1861, a species originally described from the Philippines, or sometimes by a taxonomically unjustified epithet "apulus". We therefore reexamined the taxonomic status of the Sulawesi Tropidophorus on the basis of newly obtained specimens and available museum materials. Results indicated that this island population is morphologically distinct from $T$. grayi, and we thus describe it as a new species. This species most resembles $T$. grayi by sharing a number of characteristics, such as a divided frontonasal, three preanals, and strongly keeled tail scales. However, it differs from the latter by having weaker keels on dorsal body scales, a relatively longer fourth toe with more subdigitals, and male postanal pores in a single row.
\end{abstract}

Key words: Tropidophorus grayi; New species; Scincidae; Sulawesi; Indonesia

\section{INTRODUCTION}

When two of us (TH and HO) in 1999 visited the Herpetology Section of the Natural History Museum, London, we found one scincid specimen labelled as "holotype of Tropidophorus aphilus". This specimen (BMNH 1926.10.30.71) was catalogued as being collected from Celebes (=Sulawesi) by Malcom A. Smith.

* Corresponding author. Tel: +81-75-753-4091; Fax: 075-753-4114.

E-mail address: tom@zoo.zool.kyoto-u.ac.jp
Through a personal communication with Dr. Robert F. Inger at Field Museum of Natural History, we learned that his former student, Dr. James P. Bacon, had been preparing a manuscript to describe the Sulawesi Tropidophorus, usually referred to as $T$. grayi Günther, 1861, then (see below), as a new species with holotype designation of that BMNH specimen. Unfortunately Dr. Bacon's manuscript was not completed for publication because of his death in 1986.

Recently several pet dealers, in their advertisement price catalogues on the Internet and in some hobbyists' magazines, started to refer 
to the water skink from Sulawesi as Tropidophorus apulus, most likely by erroneously copying Bacon's unpublished name, T. aphilus. However, neither of these names are actually available in accordance with International Code of Zoological Nomenclature, because the name Tropidophorus aphilus remains unpublished (see above) and the name Tropidophorus apulus, when appearing in hobbyists' magazines, has never been accompanied by information to fill the minimum requirements of the code as an original description of a new species-group name, such as that regarding the holotype and diagnostic characters (International Commission on Zoological Nomenclature, 1999).

The genus Tropidophorus belongs to the subfamily Lygosominae of the family Scincidae, and is characterized by more or less aquatic habits and a few morphological features, such as a superficially located tympanum. A total of 22 species, distributed in both continental and insular parts of Southeast Asia, are currently recognized for this genus (Smith, 1923; Taylor, 1963; Brown and Alcala, 1980; Zhao and Adler, 1993; Hikida and Ota, 1994; Manthey and Grossmann, 1997; Hikida et al., 2002). In most scientific publications except Brown and Alcala (1980: see Discussion for details), the Sulawesi population of Tropidophorus has been referred to as $T$. grayi following Rooij (1915), who first examined the taxonomic status of this island population on the basis of specimens from "Luhu and Makassar (=Ujung Pandang), Celebes" (Fig. 1). Tropidophorus grayi was originally described from the Philippines (Günther, 1961), and has been recorded from Luzon, Polillo, Leyte, Negros, Mastabe, and Cebu of this archipelago (Brown and Alcala, 1980), besides Sulawesi.

Recently one of us (AR) collected two additional specimens of Tropidophorus from South Sulawesi. Comparisons of these and other specimens from Sulawesi with specimens of $T$. grayi from the Philippines confirmed their distinct morphological differences as had been implied by Bacon's uncompleted attempt

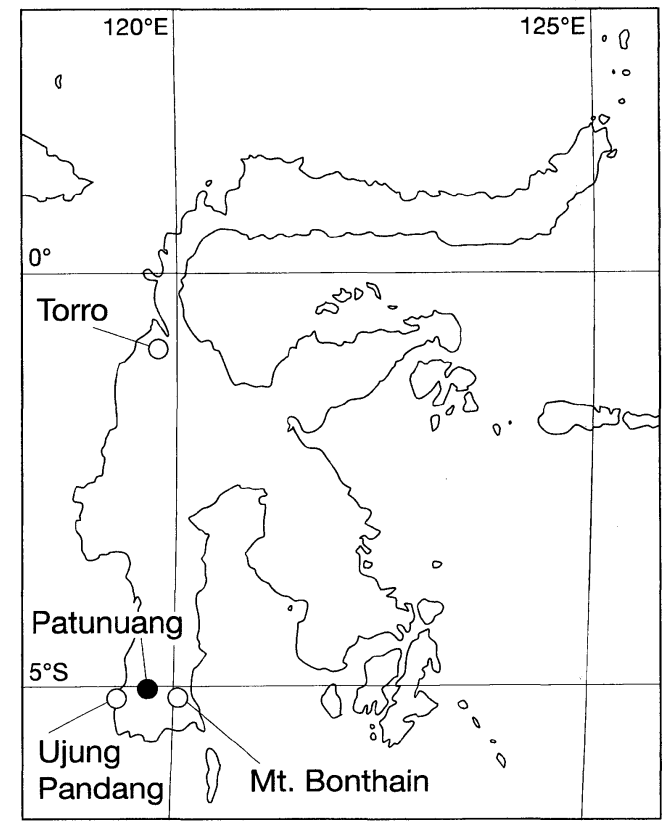

FIG. 1. Map of Sulawesi, showing sampling localities of Tropidophorus baconi sp. nov. Closed circle indicates the type locality.

(see above). We thus describe the Sulawesi population of Tropidophorus as a new species.

\section{MATERIALS AND Methods}

A total of six specimens of Tropidophorus from Sulawesi, Indonesia, were examined and compared with $22 T$. grayi from the Philippines (including three syntypes of the species and the holotype of Enoplosaurus insignis Sauvage, 1879 , a junior synonym of $T$. grayi) (see Appendix for further details of specimens used for comparisons). Comparisons with other congeneric species were made on the basis of specimens and literature referred to in our previous paper (Hikida et al., 2002).

Measurements were taken to the nearest $0.1 \mathrm{~mm}$ with dial calipers. Paravetebral scales were counted following Greer (1982). In a previous paper (Hikida et al., 2002), we proposed a new name, postsupraocular, to refer to a distinctly smaller scale behind the supraocular series, which had usually been 
treated as the fifth supraocular (Rooij, 1915) or the last supraciliary (Taylor, 1936). However, this scale was actually already discriminated from supraoculars and supraciliaries under a different name, pretemporal, by Greer and Nussbaum (2000). In the description below, we, therefore, use this reference name instead of postsupraocular. For convenience for comparisons on the basis of previously published data, we follow Taylor's (1936) definitions for other scale characters because of their broad uses in subsequent works dealing with scincid systematics and taxonomy.

Catalogue numbers of specimens deposited in the Zoological Collection of the Kyoto University Museum are preceded by KUZ. Other institutional acronyms follow Leviton et al. (1985).

Tropidophorus baconi sp. nov. Figs. 2 and 3

\section{Holotype}

MZB.Lace 3789 (Field No. AR 00053), subadult male, collected from Patunuang Natural Reserve $\left(5^{\circ} 03^{\prime} 07^{\prime \prime} \mathrm{S}, 119^{\circ} 43^{\prime} 07^{\prime \prime} \mathrm{E}\right)$, South Sulawesi, Indonesia, by A. Riyanto on 31 May 2001.

\section{Paratypes}

MZB.Lace 3788 (Field No. AR 00166), adult female, with sampling data same as the holotype; BMNH 1926.10.30.71, adult female, collected from Lowah, Mt. Bonthain, Celebes, Dutch East Indies (=South Selawesi, Indonesia), by M. A. Smith; BMNH 96.12.9.42, juvenile male, collected from Luhu (exact location not determined), Celebes, by S. and F. Sarasin; BMNH 1980.905, juvenile of unknown sex, collected from Torro, Kabupaten Donggala, Central Sulawesi (alt. $600 \mathrm{~m}$; $01^{\circ} 27^{\prime} \mathrm{S}, 19^{\circ} 59^{\prime} \mathrm{E}$ ) (collector unknomwn). KUZ R38805, adult female, obtained from a pet dealer (exact locality unknown).

\section{Diagnosis}

A relatively large Tropidophorus, 87$120 \mathrm{~mm}$ in SVL. This species differs from

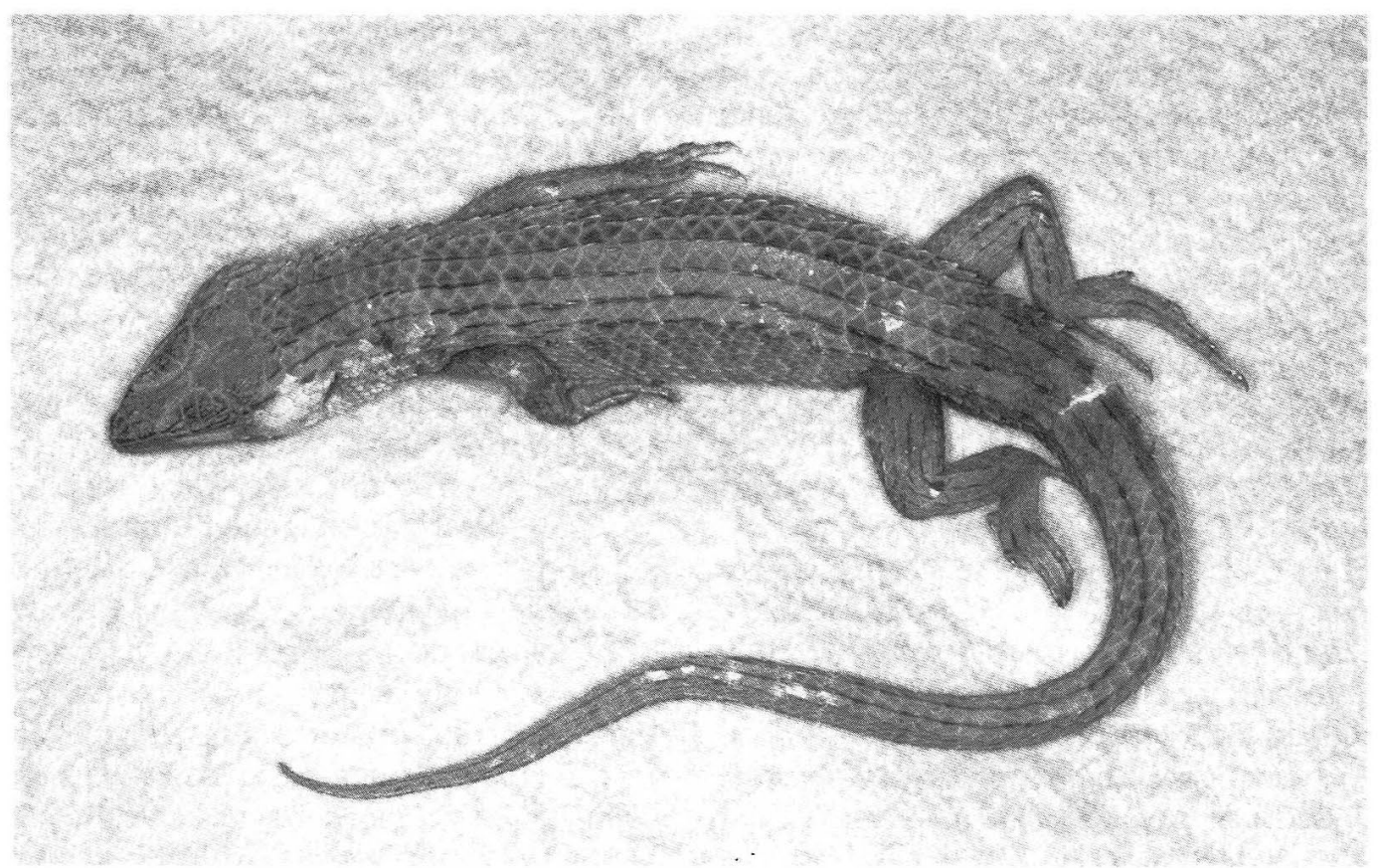

FIG. 2. Dorsal view of the holotype of Tropidophorus baconi sp. nov. (MZB.Lace 3789, $\mathrm{SVL}=87.0 \mathrm{~mm}$ ). 


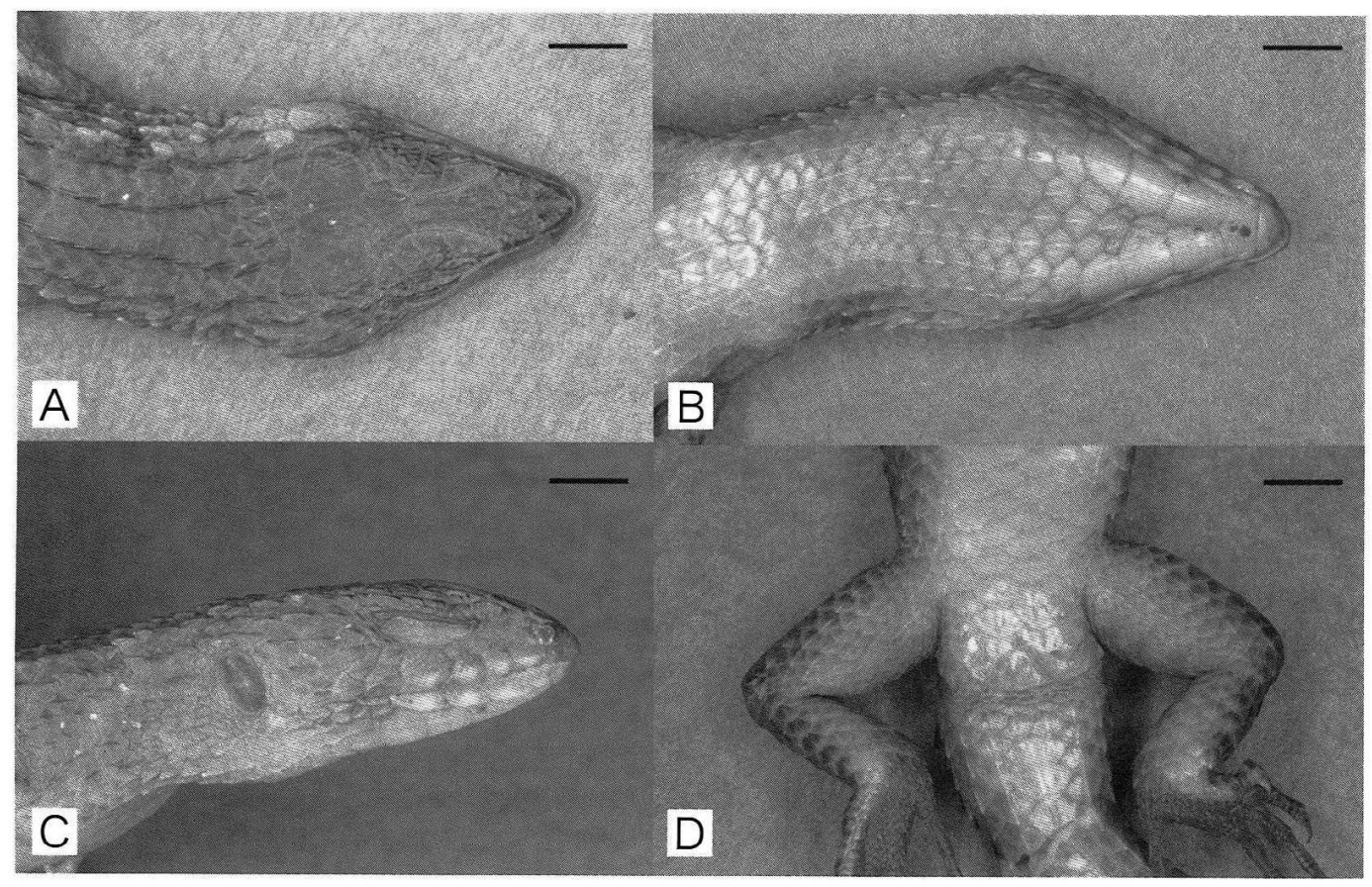

FIG. 3. Dorsal (A), ventral (B) and lateral (C) views of head, and ventral view of cloacal region (D) in the holotype of Tropidophorus baconi sp. nov. (MZB.Lace 3789). Bar equals $5 \mathrm{~mm}$.

other congeneric species except $T$. grayi by having a divided frontonasal, parietals separated from each other, lateral body scales directed obliquely upward (Fig. 4), three preanals, postanal pores in adult males, and single keels on dorsal body and tail scales with marked development of the latter to make the tail surface more or less spinose. Besides the preanal scale number, most other scale counts also largely or completely overlap between the two species (Table 1). Nevertheless, T. baconi is distinct from $T$. grayi in having relatively longer toes and more subdigitals thereon (2227 vs. $17-20$ ) with a larger number of proximal ones medially divided (8-12 vs 2-3: Fig. 5).

Tropidophorus grayi has strongly striated scales on dorsal and lateral surfaces of head, and distinctly keeled spinose scales also on dorsal surfaces of body, whereas in $T$. baconi, striations in head scales are much weaker and dorsal body scales are not spinose (Fig. 4). Postanal pores in males form a single row in $T$. baconi, but three rows in $T$. grayi (Table 1$)$.

\section{Description of holotype}

A subadult male (Fig. 2), with undeveloped testes. Temporal region on left side of head partially injured.

Head scales rugose, weakly striated; snout rounded, rostral partially visible from above, overlapping frontonasals, nasals, and first supralabials; no supranasals; frontonasal divided, overlapped by rostral, nasals, and upper anterior loreals, overlapping prefrontals; left frontonasal widely overlapped by right one; prefrontal overlapped by frontonasal and loreals, overlapping frontal, first supraocular and first superciliary; left prefrontal widely overlapped by right one; frontal large, narrowing posteriorly, overlapped by prefrontals, overlapping first and second supraoculars and frontoparietals; supraoculars four, overlapped by superciliaries; first supraocular with distinct ridge; superciliaries six, first two large, remaining four distinctly smaller; interparietal narrowing posteriorly, overlapping parietals, with small transparent spot 


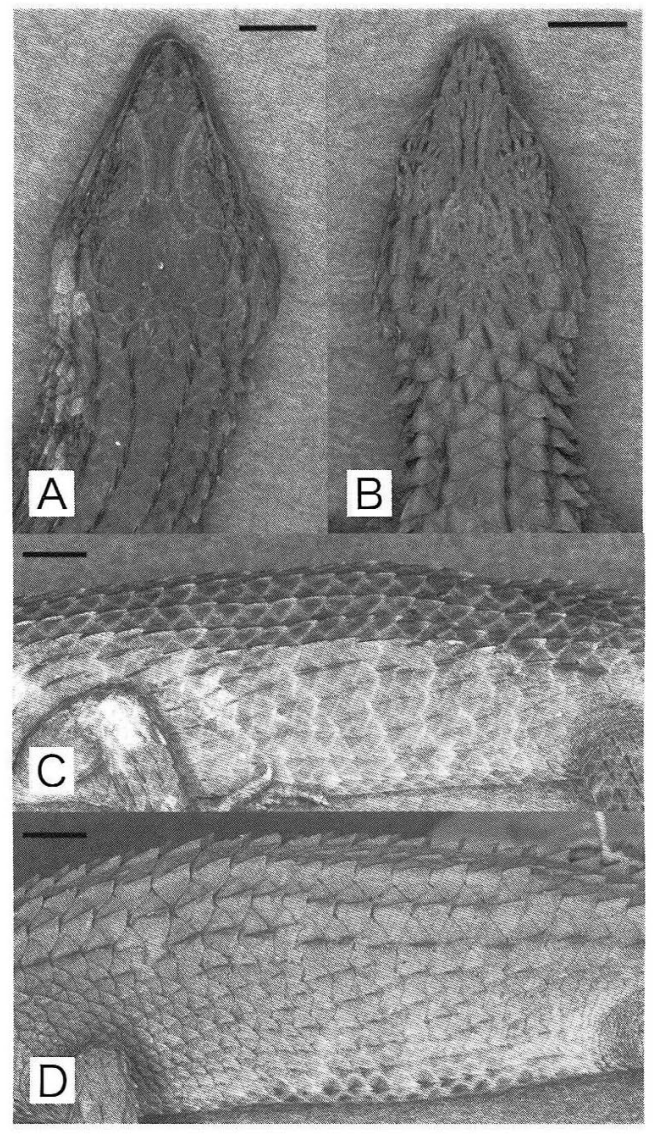

FIG. 4. Dorsal views of heads and dorsolateral views of bodies of Tropidophorus baconi sp. nov. (A and C, respectively: holotype, MZB.Lace 3789) and T. grayi from Luzon, Philippines (B and D, respectively). Bar equals $5 \mathrm{~mm}$.

showing location of parietal foramen; parietals separated by one scale; no distinct nuchals; nostril piercing nasal; nasal overlapped by rostral and first supralabial, overlapping frontonasal and loreal; anterior loreal overlapped by nasal, overlapping frontonasal, prefrontal, upper and lower posterior loreals, and second supralabial; posterior loreals divided into larger upper and smaller lower elements; supralabials seven, including four preorbital, one subocular, and two postocular ones; subocular supralabial bearing shallow groove continuing from one between preorbital supralabials and loreals; postocular supralabials keeled; presuboculars three, over-

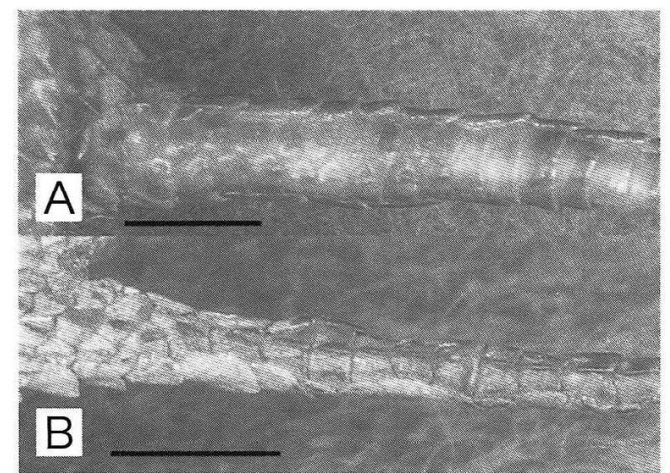

FIG. 5. Ventral views of fourth toe bases in a paratype of Tropidophorus baconi sp. nov. (A: MZB.Lace 3788 ) and T. grayi from Luzon, Philippines (B). Bars equal $2 \mathrm{~mm}$.

lapped by posterior loreal and third and fourth supralabials; one tiny scale between first presubocular and third supralabial; lower eyelid with two rows of six or seven relatively large scales, separated from subocular supralabials by one row of granular scales; postoculars three, overlapped by fourth supraocular and palpebrals, overlapping postsuboculars; pretemporal keeled, overlapped by fourth supraocular and postocular, overlapping parietal and primary temporal; postsuboculars five, keeled, first largest, overlapped by fifth supralabial and overlapping sixth supralabial; temporals keeled in four rows, those in second and third rows enlarged; uppermost secondary and tertiary temporals overlapped by parietal; tympanum superficial; mental overlapping first infralabials and postmental; postmental undivided, overlapping first chin shields; chin shields in three pairs, first left overlapped by right, second pair separated by single scale, third pair separated by three scales; infralabials six, second-fourth larger than others; midbody scales in 26 rows; tail scales in 13 rows at position of tenth subcaudal; paravertebrals (mid-dosal scales from posterior end of parietals to position just above posterior margin of thigh) 34 , as wide as neighboring scales; each of dorsal and lateral scales with single keel; scales on tail strongly keeled; dorsolateral scales on neck also 
TABLE 1. Comparisons of morphological characters between Tropidophorus baconi sp. nov. and $T$. grayi.

\begin{tabular}{lll}
\hline Character & T. baconi sp. nov. & T. grayi \\
\hline SVL & $87.0-120.0$ & $82.6-119.3^{*}$ \\
head scales & rugose & strongly striated \\
dorsal scales & not spinose & spinose \\
midbody scale rows & $24-27$ & $24-28^{*}$ \\
paravetebrals & $29-34$ & $30-34^{*}$ \\
subdigitals of 4th toe & $22-27(8-12)^{* *}$ & $16-21^{*}(2-3)^{* *}$ \\
postanal pores & 1 rows & 3 rows \\
\hline
\end{tabular}

* Including data from Brown and Alcala (1980).

** Number of divided subdigitals at base in parentheses.

strongly keeled; lateral body scales obliquely directed; ventral scales in eight rows, weakly keeled; first subcaudal divided, remaining ones entire, keeled, gradually narrowing to become as wide as neighboring scales posteriorly; preanals three, enlarged, middle one overlapped by those on both sides; postanal pores 15 , forming single row; scales on forelimb keeled, those on hind limb distinctly keeled dorsally, weakly keeled ventrally; 26-27 subdigitals beneath fourth toe, basal eight divided, remainder entire.

\section{Measurements of holotype $(\mathrm{mm})$}

Snout to vent length (SVL), 87.0; tail length, 121.0 ; axilla to groin length, 40.9 ; snout to forelimb length, 34.7; head length (tip of snout to posterior margin of parietals), 19.1; head width, 16.5; head depth, 10.7; eye length, 6.5; snout length (tip of snout to anterior corner of eye), 8.0 ; eye to ear-opening length, 8.2 ; snout to earopening length, 20.1; forelimb length, 31.5; hind limb length, 43.2; fourth toe length, 13.9; tympanum height, 4.5 ; tympanum width, 4.2.

\section{Color in preservative}

Dorsal and lateral ground color of head, body, and tail dark brown; three and six indistinct slightly lighter transverse bands on neck and dorsum of body, respectively; ventral surfaces of head and body yellowish white, slightly darker in gular region; ventral surface of tail light brown in anterior region, darker posteriorly.

\section{Variation}

Of paratypes, three adult females and two juveniles measured $89.1-120$ and $36.6-47.7 \mathrm{~mm}$ in SVL, respectively. The number of paravertebrals varied from 29 to 33 . The numbers of midbody scale rows and tail scale rows were 24-27 and 11-13, respectively. The numbers of all and divided subdigitals on fourth toe ranged from 22 to 27 and 9-12, respectively. Other scale counts were same as those in the holotype. Females had no postanal pores.

\section{Etymology}

The name is dedicated to the late Dr. James $\mathrm{P}$. Bacon in recognition of his contributions to the taxonomy of the genus Tropidophorus.

\section{Natural history}

The holotype and one female paratype (MZB.Lace 3788) were found in a small stream with a rocky bottom. When located, the holotype was resting with its body half submerged in water near the grassy shore, and the female was sitting on a large rock in the stream.

\section{Distribution}

Central and South Selawesi, Indonesia (Fig. 1). 


\section{Remarks}

Rooij (1915) first reported T. grayi from Sulawesi on the basis of specimens collected from Luhu and Makassar (Ujung Pandang). Later, Brown and Alcala (1980) did not include Sulawesi in the known range of distribution of the species, and regarded T. grayi as being endemic to the Philippines. It is thus highly likely that Brown and Alcala (1980) already supposed the Sulawesi Tropidophorus to be different from $T$. grayi, although they did not provide any reason for the above treatment. Probably, they knew of and followed Bacon's idea to recognize the Sulawesi population as a distinct species by itself (see Introduction above). Because their book (Brown and Alcala, 1980) accommodates Bacon's description of $T$. davaoensis from Mindanao, Philippines (Bacon, 1980), it is obvious that Brown and Alcala had close contact with him then.

\section{ACKNOWLEDGMENTS}

TH and HO thank M. Matsui for providing opportunities to visit museums in Europe, and AR thanks Hary Wawangningrum for her assistance with his part of this study. We are also much indebted to E. N. Arnold and C. McCarthy (BMNH), I. Ineich and A. Dubois (MNHN), G. Köhler (SMF), Siti Nuramaliati Prijono and Mumpuni Sancoyo (MZB), and H. Endo (NSMT) for allowing us to examine pertinent specimens in their care. Surveys on the European museum collections were financially supported by a Monbusho International Scientific Program, Field Research No. 10041166, (project leader: M. Matsui).

\section{LITERATURE CITED}

BACON, J. P. 1980. A new Tropidophorus from the Philipine Islands. p. 229-233. In: W. C. Brown and A. C. Alcala, Philippine Lizards of the Family Scincidae. Sillman University Press, Dumaguete City.

Brown, W. C. AND A. C. AlCala. 1980. Philip- pine Lizards of the Family Scincidae. Sillman University Press, Dumaguete City.

Greer, A. E. AND R. A. Nussbaum. 2000. New character useful in the systematics of the scincid lizard genus Mabuya. Copeia 2000: 615-618.

GÜNTHER, A. 1861. Second list of Siamese reptiles. Proc. Zool. Soc. London 1861: 187-189.

HIKIDA, T. AND H. OTA. 1994. Sphenomorphus aquaticus Malkmus, 1991, a junior synonym of Tropidophorus beccarii (Perters, 1871) (Reptilia: Squamata: Scincidae). Bonn. Zool. Beitr. 45: 57-60.

HiKIDA, T., N. ORLOV, J. NABHITABHATA, AND H. OTA. 2002. Three new depressed-bodied water skinks of the genus Tropidophorus (Lacertilia: Scincidae) from Thailand and Vietnam. Current Herpetology 21: 9-23.

INTERNATIONAL COMMISSION ON ZOOLOGICAL NOMENCLATURE. 1999. International Code of Zoological Nomenclature. International Trust for Zoological Nomenclature, London.

LEVITON, A. E., R. H. GIBBS, JR., E. HEAL, AND C. E. DAWSON. 1985. Standards in herpetology and ichthyology: part I. Standard symbolic codes for institutional resource collections in herpetology and ichthyology. Copeia 1985: 802-832.

MANTHEY, U. AND W. GRossmann. 1997. Amphibien und Reptilien Südostasiens. Natur und Tier, Münster.

RoOIJ, N. DE. 1915. The Reptiles of the IndoAustralian Archipelago. I. Lacertilia, Chelonia, Emydosauria. E. J. Brill, Leiden.

SMITH, M. A. 1923. A review of the lizards of the genus Tropidophorus on the Asiatic mainland. Proc. Zool. Soc. London, 1923: 775-781.

TAYLOR, E. H. 1936 (1935). A taxonomic study of the cosmopolitan scincoid lizards of the genus Eumeces, with an account of the distribution and relationships of its species. Univ. Kansas Sci. Bull. 24: 1-643.

TAYLOR, E. H. 1963. Lizards of Thailand. Univ. Kansas Sci. Bull. 44: 687-1077.

ZHAO, E. AND K. ADLER. 1993. Herpetology of China. Contribution to Herpetology, 10. Society for the Study of Amphibians and Reptiles, Oxford, Ohio. 


\section{APPENDIX}

Specimens of Tropidophorus grayi from the Philippines examined for comparisons

BMNH 1946.8.20.86-88 (syntypes of Tropidophorus grayi Günther 1861), BMNH 72.8.20.5-7; Luzon: MNHN 5443 (holotype of Enoplosaurus insignis Sauvage, 1870),
MNHN 1900-350, BMNH 72.8.20.81, 95.11.7.12, SMF 15752-3, NSMT 03845; Cebu, SMF 15751; Unknown localities (probably Philippines): MNHN1997.3707-14, from a pet dealer.

Accepted: 25 June 2003 